attached to the mask, and both are placed over the patient's face. From this time on the anesthesia is by the ordinary drop method, except that instead of dropping ether on the mask, it is dropped through the brass tube inside the coil, and so reaches the mask proper as a warm gas. The only caution at this period is to give the ether more slowly and in smaller amounts than by the cold method, as it reaches the patient more quickly and more is available to the patient after being heated than when it is dropped cold on the mask. Towels may be placed about the mask as desired, but in the majority of cases they are not required, and in practically all they may be removed as soon as full narcosis is reached. In this way we give an abundance of air to the patient and as a result have little cyanosis. The patient's good color throughout has been quite remarkable. During the period the anesthetic is being crowded, a little of the ether may reach the gauze of the mask unchanged; but the coil will speedily regain its temperature as soon as the rate of administration can be somewhat slackened, and will again convert all of the ether to a gas. As the patient breathes, warm air is inhaled and exhaled, as can be readily noted, a quite different matter from breathing through a mask covered with ice crystals of the exhaled breath.

As to the results in the employment of this method, I have observed the following:

1. The patient goes to sleep more easily without coughing or holding his breath.

2. There is an absence of second stage excitement in the great majority of cases.

3. It is a dry anesthesia, with absence of mucus from the air passages, except in the deepest prolonged anesthesia.

4. Anesthesia is easily maintained.

5. As a rule, the patient is brighter on awakening and awakens in a shorter time.

6. Postoperative nausea and vomiting are absent.

7. By reason of conserved bodily heat we should expect shock to be less; and this conservation, together with absence of bronchial irritation, tends to lessen the occurrence of postoperative ether pneumonia and bronchitis.

8. The total amount of ether used is diminished by approximately one-half.

\section{AN ACTUAL POCKET MERCURIAL SPHYGMOMANOMETER}

Hugh Hamilton, M.D., Harrisburg, Pa

I have found the various sorts of blood pressure instruments defective in one essential-all are bulky. Of the two kinds of mercurial and dial gages, the mercurial is esteemed the best. In an effort to devise an instrument which could be carried on the person without exciting curiosity in private practice, the one illustrated resulted.

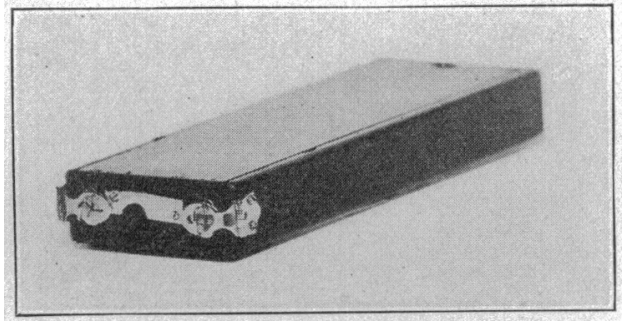

Fig. 1.-Pocket mercurial sphygmomanometer closed.

The mercurial hinge cock for the mercury is from an instrument made by Tagliabue. I claim only reduction in bulk and consequent mechanical arrangements, the whole apparatus weighing about 1 pound.

The photographs are precisely at the identical focus. Therefore the comparative size open and shut is represented in true proportion.

After careful comparison the mercurial column may be regarded as the most certain to give true results because it is fixed at a zero by gravity and not through artificial stand- ards essential in all other devices dominated by springs as dial instruments, that may some time or other lose the zero, which automatic quicksilver will not do. In this little box I have added beside the $U$ tube a thermometer for the room temperature. At the time of taking an observation of a "pressure" the body temperature is also then noted; across the space in the $U$ tube about midway a level is inserted in the wooden support.

The wooden support for the $U$ manometer of the sphygmomanometer is a free lid to the box. The edge under the

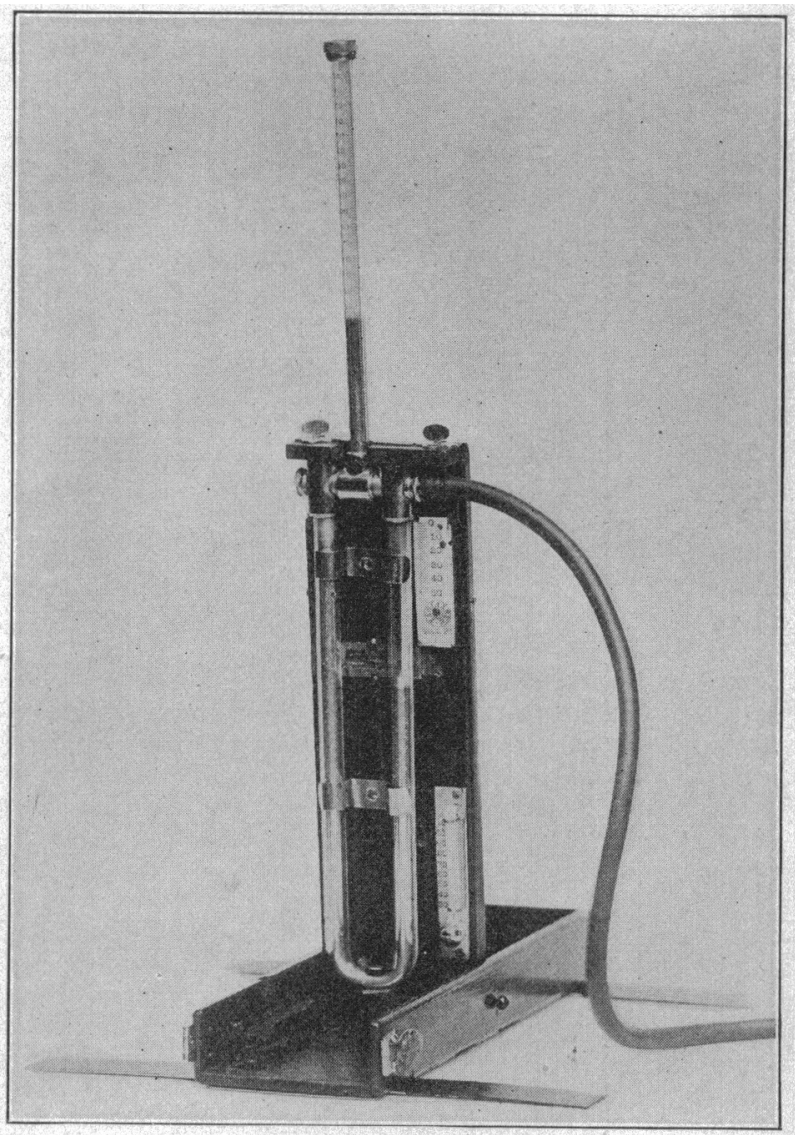

Fig. 2.-Pocket mercurial sphygmomanometer open for use.

curve of the $U$ fits upright into a slot in the center of the box, fastened by braces rising from opposite ends of the box. On the bottom of the box are four blades that extend at right angles to the length of the box resembling when opened "a turtle." This little box is $8 \mathrm{r} / 2$ inches long, $23 / 4$ inches wide and $13 / 4$ inches thick or 22 by 7 by $3 \mathrm{~cm}$. The hope is that this small (actual pocket) case may make the employment of the accurate mercarial sphygmomanometer available in clinical private practice and assist all in more precise prognoses.

\section{ADJUSTABLE SPLINT FOR FRACTURES ABOUT THE ELBOW JOINT-CONVENIENT STAND FOR THE DIAGNOSIS OF PES PLANUS*}

Willis E. Hartshorn, M.D., New Haven, Conn.

ADJUSTABLE SPLINT FOR FRACTURES ABOUT THE ELBOW JOINT

Fractures of the external and internal condyles of the humerus, $T$-fractures into the elbow joint and comminuted fractures in this region often afford occasions in which an adjustable angular splint can be used to great advantage. The splint, a description of which is here outlined, is distinctly a simple affair which can be made by any one in a comparatively short time. This fact offers the chief reason for its presentation. It consists of two wooden splints $A$ and $B$ (Fig. 1), the length varying in children and adults. These

* From the Surgical Service of the New Haven Dispensary. 